\title{
High suPAR and Low Blood Eosinophil Count are Risk Factors for Hospital Readmission and Mortality in Patients with COPD
}

This article was published in the following Dove Press journal: International Journal of Chronic Obstructive Pulmonary Disease

\author{
Kjell E J Håkansson (D) \\ Charlotte S Ulrik (D) ${ }^{1,2}$ \\ Nina S Godtfredsen (ID) ${ }^{1,2}$ \\ Thomas Kallemose $\mathbb{D}^{3}$ \\ Ove Andersen (iD ${ }^{2-4}$ \\ Jesper Eugen-Olsen (iD ${ }^{3}$ \\ Kristoffer Marsaa $\left.{ }^{5}\right)^{5}$ \\ Line JH Rasmussen (1D) 3,6 \\ 'Department of Respiratory Medicine, \\ Copenhagen University Hospital Amager \\ and Hvidovre, Hvidovre, Denmark; \\ ${ }^{2}$ Institute of Clinical Medicine, University \\ of Copenhagen, Copenhagen, Denmark; \\ ${ }^{3}$ Clinical Research Centre, Copenhagen \\ University Hospital Amager and \\ Hvidovre, Hvidovre, Denmark; \\ ${ }^{4}$ Emergency Department, Copenhagen \\ University Hospital Amager and \\ Hvidovre, Hvidovre, Denmark; ${ }^{5}$ Palliative \\ Unit, Copenhagen University Hospital \\ Herlev and Gentofte, Herlev, Denmark; \\ ${ }^{6}$ Department of Psychology and \\ Neuroscience, Duke University, Durham, \\ NC, USA
}

Introduction: The biomarker soluble urokinase plasminogen activator receptor (suPAR) has been associated with increased mortality in chronic obstructive pulmonary disease (COPD), while elevated blood eosinophils have been associated with better survival. We hypothesized that suPAR and blood eosinophil count are independent risk factors for readmission and mortality after an acute admission in patients with COPD.

Methods: This retrospective cohort study comprised 4022 patients with prevalent COPD acutely admitted to Hvidovre Hospital, Denmark. Irrespective of cause of admission, suPAR and blood eosinophils were measured, and patients were followed up to 365 days. Associations with 365-day respiratory readmission, all-cause readmission and all-cause mortality were investigated by Cox regression analyses adjusted for age, sex, Charlson score and C-reactive protein.

Results: suPAR was significantly elevated in patients who later experienced readmission or died. At 365 days, hazard ratios (HRs) for all-cause readmission and mortality reached 1.61 (95\% CI $1.40-1.85 ; \mathrm{p}<0.0001)$ and 3.40 (95\% CI 2.64-4.39; $<0.0001)$, respectively, for COPD patients in the fourth suPAR quartile compared to patients in the first suPAR quartile. High blood eosinophils $(>300$ cells $/ \mu \mathrm{L}$ ) were associated with lower risk of mortality (HR $0.49,95 \%$ CI $0.39-0.62$; $\mathrm{p}<0.0001)$ compared with patients with $<150$ cells $/ \mu \mathrm{L}$. When stratifying patients by suPAR quartiles and blood eosinophil counts, the highest relative mortality rate was found in patients belonging to both the fourth suPAR quartile and the low blood eosinophil $(<150$ cells $/ \mu \mathrm{L})$ group. Conclusion: In this cohort of COPD patients acutely admitted to a hospital, elevated suPAR concentrations were associated with both higher risk of all-cause readmission and mortality, whereas higher blood eosinophil count was associated with lower risk of mortality.

Keywords: acute admission, biomarker, hospitalization, prognosis, retrospective cohort, inflammation

\section{Introduction}

Chronic obstructive pulmonary disease (COPD) is one of the world's most common chronic diseases, posing a considerable economic and social burden worldwide. ${ }^{1}$ COPD is characterized by a decline in lung function and overall health status as well as acute exacerbations of COPD (AECOPD). As COPD progresses, patients often experience repeated hospitalizations due to exacerbations and comorbidities. Besides major impacts on quality of life and healthcare-associated costs, ${ }^{2}$ all-cause readmissions have been shown to be an independent risk factor of COPD mortality. ${ }^{3,4}$ This highlights the need for novel risk prediction tools to help identifying hospitalized COPD patients at high risk of future readmission and mortality.
Correspondence: Kjell E J Håkansson Department of Respiratory Medicine, Copenhagen University Hospital Amager and Hvidovre, Kettegård Allé 30 2650,

Hvidovre, Denmark

Tel +452l438688

Email kjell@kjell.dk 
Several prognostic markers for hospitalization and/or COPD-related mortality have been suggested, such as presence of emphysema and severity of airflow limitation, ${ }^{5,6}$ but reliable biomarkers for COPD readmission and mortality risk are yet to be found. suPAR is the soluble form of the urokinase plasminogen activator receptor (UPAR), a membrane receptor consisting of three domains $\left(\mathrm{D}_{\mathrm{I}}, \mathrm{D}_{\mathrm{II}}\right.$ and $\left.\mathrm{D}_{\mathrm{III}}\right)$. uPAR is expressed on a range of cells such as lymphocytes, monocytes, endothelial and smooth muscle cells, where uPAR and its soluble form are a central part of the plasmin/ plasminogen pathway and are involved in chemotaxis, immune system activation and tissue remodeling. As such, suPAR is considered a broadly applicable inflammatory marker in both acute and chronic disease with associations ranging from diabetes and arrhythmias to acute all-cause mortality. ${ }^{7-9}$

In COPD, suPAR is associated with small airway fibrosis and emphysema through complex molecular and genetic pathways, ${ }^{10}$ and neutrophils are thought to be a central source of circulating suPAR. ${ }^{11,12}$ Furthermore, studies have shown that suPAR is elevated in patients with stable COPD compared to healthy controls, ${ }^{13}$ as well as being a biomarker of poor prognosis and increased 90-day mortality in COPD patients in an emergency department (ED) setting. ${ }^{14}$

Another area of interest in COPD biomarkers are eosinophils, neutrophils and their resulting inflammatory profiles. Both types of inflammation have been associated to adverse outcomes in (AE)COPD. ${ }^{15-17}$ In eosinophilic inflammation, higher and, in particular, fluctuating blood eosinophil counts have been suggested as risk markers for unstable disease and exacerbations. ${ }^{18}$ The GOLD 2019 guidelines have introduced blood eosinophil count as a possible biomarker to identify at-risk patients and candidates for inhaled corticosteroid treatment. ${ }^{1}$ Despite the recent surge in inflammatory profile research and the roles of eosinophils and other inflammation markers in COPD, our knowledge of their roles in clinical outcomes is still limited. Furthermore, little is known about the relationship between suPAR and blood eosinophils, but with suPAR being thought to stem from activated neutrophils, ${ }^{11}$ we hypothesize that they may reflect separate inflammatory mechanisms and as such provide distinct clinical information about adverse outcomes in COPD when measured in combination.

We have previously shown that suPAR is associated with 30- and 90-day mortality in acutely admitted patients with COPD. ${ }^{14}$ Here, we hypothesize that plasma suPAR and blood eosinophil count are independently associated with both long-term (365-days) readmission and mortality in patients acutely admitted with COPD as either primary or secondary diagnosis.

\section{Materials and Methods Ethics}

The study was approved by the Danish Health and Medicines Authority (ref. 3-3013-1061/2) and the Danish Data Protection Agency (ref. HVH-2014-018, 02767).

\section{Study Subjects and Study Design}

This study is based on a retrospective, registry-based cohort study of 29,088 medical patients who were acutely admitted to the ED, Copenhagen University Hospital Amager and Hvidovre, Hvidovre, Denmark, from November 18, 2013, to March 17, 2017. The follow-up period ended June 17, 2017, ensuring follow-up of minimum 90 days for all patients. The ED receives unselected, adult internal medicine patients of all specialties except patients suspected of gastroenterological diseases, as previously described. ${ }^{14}$ In this study, we included all patients who 1) were admitted to the ED during the study period, 2) had a diagnosis of COPD (ICD-10: J440, J441, J449) registered before (within the past 2 years) or during the admission, and 3 ) had suPAR concentrations measured as part of the standard admission blood tests. suPAR and mortality data on a subgroup $(n=2838)$ of this COPD cohort has previously been published. ${ }^{14}$

The index admission was defined as the first admission where a patient had suPAR measured. Data on suPAR and blood eosinophil count were obtained via the electronic hospital database LABKA. All data on diagnoses and admissions were obtained from the Danish National Patient Registry. Vital status was obtained from the Danish Civil Registration System. ${ }^{19}$ Follow-up was at 30, 90 or 365 days. The Charlson comorbidity index (Charlson score) was used to create a compound score of disease burden due to comorbidities, based on concurrent ICD-10 diagnoses on a perpatient basis. The score was used to correct for co/multimorbidity in our multivariate analyses and was calculated using a SAS macro ${ }^{20}$ with updated weights as defined by Quan et al. ${ }^{21}$ All primary and secondary diagnoses registered in the National Patient Registry for the past 2 years before the index admission were used to calculate the score. The 17 original Charlson groups were collapsed into 9 major comorbidity groups (the Charlson group "Chronic Pulmonary Disease" was omitted): Cardiovascular disease (comprised of the Charlson groups "Myocardial Infarction", "Congestive 
Heart Failure", "Peripheral Vascular Disease", and "Cerebrovascular Disease"), "Dementia", "Peptic Ulcer Disease", Liver Disease ("Mild Liver Disease" and "Moderate or Severe Liver Disease"), Diabetes ("Diabetes without Chronic Complications", "Diabetes with Chronic Complications"), "Renal Disease", Cancer ("Cancer", "Metastatic Carcinoma"), and Other ("Connective Tissue Disease-Rheumatic Disease", "Hemiplegia and Paraplegia", "AIDS/HIV"). In addition, we registered whether patients had a history of acute exacerbations (ICD-10: J441) in the past 2 years before the index admission, and whether the following specific comorbidities were present in the past 2 years before or during the index admission: Hypertension (ICD-10: I10-I15), Myocardial Infarction (ICD-10: I21, I22, I252), Stroke (ICD-10: I61, I63, I649), Type 2 Diabetes (ICD-10: E11), and Lung Cancer (ICD-10: C34). We identified causes of admissions as A-diagnoses (primary diagnoses) registered for the index admission or readmissions, based on ICD-10 chapters, as shown in Table 2. In addition, we identified the following specific respiratory diagnoses as causes of admissions/readmissions: acute upper respiratory infections (ICD-10: J00-06), influenza or pneumonia (ICD10: J09-18), other acute lower respiratory infections (ICD10: J20-22), chronic lower respiratory diseases (ICD-10: J40-47), acute respiratory distress syndrome or pulmonary edema (ICD-10: J80-81), other interstitial pulmonary diseases (ICD-10: J84), pleural effusion (ICD-10: J90-91), pneumothorax (ICD-10: J93), and respiratory failure (ICD10: J96). It should be noted that a patient can have more than one cause of admission/readmission, e.g., if a patient was transferred between wards during the admission.

\section{Measurements}

Admission blood tests were analyzed at the Department of Clinical Biochemistry, Hvidovre Hospital. Plasma suPAR concentrations were measured using the suPARnostic AUTO Flex ELISA kit (ViroGates A/S, Birkerød, Denmark). ${ }^{7}$ The suPARnostic ${ }^{\circledR}$ ELISA measures the full length $\left(\mathrm{D}_{\mathrm{I}}-\mathrm{D}_{\mathrm{III}}\right)$ and the cleaved $\left(\mathrm{D}_{\mathrm{II}} \mathrm{D}_{\text {III }}\right)$ suPAR molecules. Blood eosinophil counts were measured using Sysmex XE5000 (Sysmex Corporation, Kobe, Japan; until February 2015) and Sysmex XN9000 (from February 2015) analyzers. C-reactive Protein (CRP) was measured using a COBAS 6000 analyzer (Roche Diagnostics, Mannheim, Germany).

\section{Statistical Analyses}

Primary outcomes were acute (unplanned) readmission and all-cause mortality within 365 days from the index admission. Secondary outcomes were identical outcomes within 30 or 90 days. Data on secondary outcomes are presented in the Supplementary Material. For readmissions, we examined all-cause readmissions and respiratory readmissions (i.e., the first readmission for any of the following respiratory ICD-10 diagnoses, regardless of whether another non-respiratory readmission had transpired before: J00-06, J09-18, J20-22, J40-47, J80-81, J84, J90-91, J93, J96).

Continuous variables are presented as median and interquartile range (IQR), and categorical variables are presented as number (n) and percentages (\%).

Population-specific suPAR quartiles were generated. To create categorical blood eosinophils groups, cut-offs were defined as low eosinophils $(<150$ cells $/ \mu \mathrm{L})$, intermediate eosinophils (150-300 cells $/ \mu \mathrm{L})$ and high eosinophils (>300 cells/ $\mu \mathrm{L}){ }^{1,22,23}$ Results from blood eosinophil analyses were available for $97.5 \%$ of the patients.

Unadjusted and multivariable adjusted Cox regression analyses were used to estimate the association of suPAR, continuous ( $\log 2$-transformed) and categorical (quartiles), with risk of readmission and mortality in separate models. Similar models were fitted for eosinophils (log2-transformed or low/intermediate/high blood eosinophil count). Results are presented as hazard ratios (HRs) with 95\% confidence intervals (CIs). The adjusted models include the following variables: age, sex, Charlson score, CRP, suPAR and eosinophils. In the Cox regression analyses of readmission, death before readmission was considered a competing endpoint. The HR for readmission is therefore calculated for the causespecific hazard of readmission, with censoring at the time of death. The proportional hazards assumption was evaluated by the Schoenfeld residuals; if fits violated the assumption, modifications were made to the model by stratifying the hazard by the adjusted variables. The discriminative ability of suPAR and blood eosinophil count to predict 365-day readmission and mortality was analyzed using area under the curve (AUC) for receiver operating characteristics (ROC) curves. We calculated sensitivity, specificity, positive predictive value (PPV), and negative predictive value (NPV) at cut-off values determined using Youden's index ${ }^{24}$ or the cut-off for the highest suPAR quartile or 150 cells $/ \mu \mathrm{L}$ for blood eosinophil count. 
Cumulative incidence plots for survival and readmission stratified by suPAR quartiles are presented to illustrate the outcome distribution of COPD patients over time.

SAS Enterprise Guide 7.11 (SAS Institute Inc, Cary, NC) and R 3.60 (R Foundation for Statistical Computing, Vienna, Austria) were used for statistical analysis. R 3.60 was used to create the figures. A P-value $<0.05$ was considered statistically significant.

\section{Results}

A total of 29,088 patients were admitted to the ED and had suPAR analyzed during the study period. Of these patients, 4022 (55.5\% women, median age 73.1 years) had a prevalent COPD diagnosis and were included in the present study. The median length of stay was 2.1 days (Table 1 ).

The most common comorbidities were cardiovascular diseases (25.1\%) and diabetes (13.4\%). Of all patients, $19.5 \%$ had a history of at least one acute exacerbation within the past two years (Table 1). For half of the patients, the primary cause of index admission was respiratory disease $(\mathrm{n}=1982,49.3 \%)$, with the most common diagnosis being chronic lower respiratory disease $(\mathrm{n}=941)$ (Table 2$)$.

At the index admission, COPD patients had a median suPAR of $3.9 \mathrm{ng} / \mathrm{mL}$ and a median blood eosinophil count of 100 cells $/ \mu \mathrm{L}$ (Table 1). The mean follow-up time was 297.8 days (SD 125.6). During this period, 2326 patients (57.8\%) were readmitted for any cause (of which 938 (40.3\%) were due to respiratory diagnoses), and 1268 patients $(31.5 \%)$ had a respiratory readmission (Table 2 ). Of the patients, $26.1 \%$ died within 365 days (Table 3).

\section{suPAR in COPD}

COPD patients who were readmitted due to respiratory diagnoses had significantly higher median suPAR at the time of index admission compared to event-free patients (4.0 $(2.9-5.5)$ vs $3.3(2.6-4.4) \mathrm{ng} / \mathrm{mL}, \mathrm{p}<0.0001)$. Similarly for all-cause readmissions, patients who were later readmitted had significantly higher median suPAR at the time of index admission compared to event-free patients (4.1 (IQR 3.0-5.7) vs 3.3 (IQR 2.6-4.4) ng/mL, p<0.0001) (Table 3). When stratified into suPAR quartiles, higher readmission rates were observed with increasing suPAR quartiles (Figure 1).

In univariate Cox regression analyses, elevated suPAR was associated with increased risk of both respiratory and all-cause readmission in COPD patients (Table 4). When adjusting for age, sex, Charlson score, CRP and blood eosinophils, only all-cause readmission remained
Table I Baseline Characteristics of Patients Acutely Hospitalized with Prevalent COPD

\begin{tabular}{|l|l|}
\hline & N (\%) or \\
& Median (IQR) \\
\hline Total N & 4022 \\
Men & $1803(44.8 \%)$ \\
Women & $2219(55.2 \%)$ \\
Age (years) & $73.1(63.7-81.1)$ \\
\hline Comorbidities: & \\
Hypertension ${ }^{\text {a }}$ & $1009(25.1 \%)$ \\
Cardiovascular disease & $1010(25.1 \%)$ \\
$\quad$ Myocardial infarction & $165(4.1 \%)$ \\
$\quad$ Stroke & $224(5.6 \%)$ \\
Dementia & $162(4.0 \%)$ \\
Peptic ulcer disease & $101(2.5 \%)$ \\
Liver disease (mild and moderate/severe) & $113(2.8 \%)$ \\
Diabetes (with and without complications) & $538(13.4 \%)$ \\
$\quad$ Type 2 diabetes & $520($ I2.9\%) \\
Renal disease & $148(3.7 \%)$ \\
Cancer & $448(I 1.1 \%)$ \\
$\quad$ Lung cancer & $149(3.7 \%)$ \\
Other comorbidities ${ }^{b}$ & $97(2.4 \%)$ \\
Charlson score & $1(I-2)$ \\
History of acute exacerbations in past 2 years & $785(19.5 \%)$ \\
Length of hospital stay (days) & $2.1(0.6-6.7)$ \\
C-reactive protein (mg/L), $\mathrm{n}=3848$ & $16.0(4.0-65.0)$ \\
Blood eosinophil count (cells/ $\mu \mathrm{L}), \mathrm{n}=3849$ & $100(20-220)$ \\
suPAR (ng/mL) & $3.9(2.9-5.6)$ \\
\hline
\end{tabular}

Notes: "The category "Hypertension" was defined as ICD-10 diagnoses II0-II5 and was not part of the Charlson score. "The category "Other comorbidities" includes the Charlson groups connective tissue disease - rheumatic isease $(n=72)$, hemiplegia and paraplegia $(n=17)$, and AIDS/HIV $(n=9)$.

Abbreviations: COPD, chronic obstructive pulmonary disease; IQR, interquartile range; suPAR, soluble urokinase plasminogen activator receptor.

associated with suPAR (365 days HR for fourth vs first suPAR quartile: $1.61,95 \%$ CI 1.40-1.85) (Table 4).

COPD patients who died during follow-up had significantly higher median SUPAR at the time of index admission compared to event-free patients (5.3 (IQR 3.8-7.1) vs 3.3 $\mathrm{ng} / \mathrm{mL}$ (IQR 2.6-4.4) ng/mL, $\mathrm{p}<0.0001$ ) (Table 3). All-cause mortality increased with increasing suPAR quartiles (Figure 1), reaching an HR of 3.40 (95\% CI 2.64-4.39) in the fourth quartile vs the first quartile at 365 days after adjusting for age, sex, Charlson score, CRP and blood eosinophils (Table 4).

In ROC curve analyses, the AUCs for suPAR were 0.53 (95\% CI 0.51-0.55) for predicting all-cause readmission (Supplementary Figure 1) and 0.71 (95\% CI 0.69-0.72) for predicting mortality (Supplementary Figure 2).

The clinical performance of suPAR was evaluated using sensitivity/specificity analyses for cut-offs determined by 1) Youden's index (YI) and 2) the fourth 
Table 2 Causes of Index Admission and 365-Day Readmission in 4022 Patients with Prevalent COPD

\begin{tabular}{|c|c|c|c|}
\hline & Index Admissions N (\%) & First Readmission N (\%) & $\begin{array}{l}\text { Total Respiratory } \\
\text { Readmissions N (\%) }\end{array}$ \\
\hline $\begin{array}{l}\text { Total events } \\
\text { Certain infections and parasitic diseases } \\
\text { Endocrine, nutritional and metabolic diseases } \\
\text { Circulatory diseases }\end{array}$ & $\begin{array}{l}4022(100) \\
191(4.7) \\
139(3.5) \\
441(11.0)\end{array}$ & $\begin{array}{l}2326 \\
132(5.7) \\
110(4.7) \\
252(10.8)\end{array}$ & 1268 \\
\hline $\begin{array}{l}\text { Respiratory diseases } \\
\text { Acute upper respiratory infections } \\
\text { Influenza or pneumonia } \\
\text { Other acute lower respiratory infections } \\
\text { Chronic lower respiratory diseases } \\
\text { Acute respiratory distress syndrome or pulmonary edema } \\
\text { Other interstitial pulmonary diseases } \\
\text { Pleural effusion } \\
\text { Pneumothorax } \\
\text { Respiratory failure }\end{array}$ & $\begin{array}{l}1982(49.3) \\
17(0.9)^{\mathrm{a}} \\
501(25.3)^{\mathrm{a}} \\
21(1.1)^{\mathrm{a}} \\
941(47.5)^{\mathrm{a}} \\
6(0.3)^{\mathrm{a}} \\
4(0.2)^{\mathrm{a}} \\
17(0.9)^{\mathrm{a}} \\
16(0.8)^{\mathrm{a}} \\
542(27.3)^{\mathrm{a}}\end{array}$ & $\begin{array}{l}938(40.3) \\
2(0.2)^{\mathrm{a}} \\
252(26.9)^{\mathrm{a}} \\
4(0.4)^{\mathrm{a}} \\
432(46.1)^{\mathrm{a}} \\
4(0.4)^{\mathrm{a}} \\
3(0.3)^{\mathrm{a}} \\
7(0.7)^{\mathrm{a}} \\
9(1.0)^{\mathrm{a}} \\
300(32.0)^{\mathrm{a}}\end{array}$ & $\begin{array}{l}5(0.4) \\
370(29.2) \\
7(0.6) \\
554(43.7) \\
4(0.3) \\
5(0.4) \\
11(0.9) \\
10(0.8) \\
406(32.0)\end{array}$ \\
\hline $\begin{array}{l}\text { Diseases of the digestive system } \\
\text { Musculoskeletal and connective tissue disease } \\
\text { Diseases of the genitourinary system } \\
\text { Symptoms, signs, and abnormal findings } \\
\text { Factors influencing health status and contact with health services } \\
\text { Other causes of admission }{ }^{\text {b }}\end{array}$ & $\begin{array}{l}108(2.7) \\
104(2.6) \\
119(3.0) \\
372(9.2) \\
416(10.3) \\
338(8.4)\end{array}$ & $\begin{array}{l}121(5.2) \\
56(2.4) \\
94(4.0) \\
283(12.2) \\
208(8.9) \\
316(13.6)\end{array}$ & \\
\hline
\end{tabular}

Notes: aPercent of Respiratory disease (re)admissions. 'Causes of admission are based on ICD-I0 chapters. The category "Other causes of admission" includes the ICD-10 chapters: II "Neoplasms" and III "Diseases of the blood and blood-forming organs and certain disorders involving the immune mechanism" ( $\mathrm{n}=89 \mathrm{for}$ index admissions; $\mathrm{n}=79$ for readmissions); $V$ "Mental and behavioral disorders" ( $n=90$ for index admissions; $n=54$ for readmissions); Vl "Diseases of the nervous system" ( $n=35$ for index admissions; $n=37$ for readmissions); VII "Diseases of the eye and adnexa" and VIII "Diseases of the ear and mastoid process" ( $n=8$ for index admissions; $n=3$ for readmissions); XII "Diseases of the skin and subcutaneous tissue" ( $n=20$ for index admissions; $n=19$ for readmissions); XV "Pregnancy, childbirth and the puerperium" ( $n=I$ for index admissions; $n=3$ for readmissions); and XIX "Injury, poisoning and certain other consequences of external causes" ( $n=98$ for index admissions; $n=I 27$ for readmissions). It should be noted that a patient can have more than one cause of admission/readmission, e.g., if a patient was transferred between wards during the admission.

Abbreviation: COPD - Chronic obstructive pulmonary disease.

suPAR quartile cut-off. For predicting 365-day all-cause readmission, a sensitivity of $54.3 \%$ and a specificity of $54.5 \%$ (PPV 62.2\%, NPV 46.4\%) were achieved using the YI optimal cut-off of $3.9 \mathrm{ng} / \mathrm{mL}$. Using the fourth quartile cut-off $(5.6 \mathrm{ng} / \mathrm{mL})$ yielded a sensitivity of $26.7 \%$ and specificity 76.2\% (PPV 60.8\%, NPV 43.0\%).

For 365 -day mortality, a sensitivity of $63.6 \%$ and a specificity of $68.8 \%$ (PPV 41.9\%, NPV 84.2\%) were

Table 3 Rates of Readmission and Mortality Within 365 Days in 4022 Patients with COPD Following Hospitalization Stratified by suPAR Quartiles or Blood Eosinophil Counts

\begin{tabular}{|c|c|c|c|c|}
\hline & No Event & Respiratory Readmission & All-Cause Readmission & All-Cause Mortality \\
\hline & 1275 (31.7\%) & 1268 (31.5\%) & $2326(57.8 \%)$ & $105 \mid(26.1 \%)$ \\
\hline $\operatorname{suPAR}(\mathrm{ng} / \mathrm{mL})$ & $3.3(2.6-4.4)$ & $4.0(2.9-5.5)^{*}$ & 4.I $(3.0-5.7)^{*}$ & $5.3(3.8-7.1)^{*}$ \\
\hline First quartile $(<2.9), n=980$ & 437 (44.5\%) & 309 (31.5\%) & $511(52.1 \%)$ & 109 (11.1\%) \\
\hline Second quartile (2.9-3.8), $n=1003$ & $388(38.7 \%)$ & $286(28.5 \%)$ & $551(54.9 \%)$ & 175 (17.4\%) \\
\hline Third quartile (3.9-5.5), $\mathrm{n}=1014$ & $268(26.4 \%)$ & $365(36.0 \%)$ & $643(63.4 \%)$ & $287(28.3 \%)$ \\
\hline Fourth quartile $(\geq 5.6), n=1025$ & $182(17.8 \%)$ & $308(30.0 \%)^{*}$ & $621(60.6 \%)^{*}$ & $480(46.8 \%)^{*}$ \\
\hline Eosinophils (cells/ $\mu \mathrm{L})$ & $120(30-250)$ & $100(20-240)^{*}$ & $100(30-230)^{*}$ & $50(10-150)^{*}$ \\
\hline Low $(<150), n=2366$ & $678(28.7 \%)$ & $735(31.1 \%)$ & 1367 (57.8\%) & $746(31.5 \%)$ \\
\hline Intermediate $(150-300), \mathrm{n}=886$ & $312(35.2 \%)$ & $266(30.0 \%)$ & $520(58.7 \%)$ & $169(19.1 \%)$ \\
\hline High (>300), n=597 & $222(37.2 \%)$ & $218(36.5 \%)^{*}$ & $354(59.3 \%)^{*}$ & $86(14.4 \%)^{*}$ \\
\hline
\end{tabular}

Notes: Values presented as percentages or median (IQR). Chi ${ }^{2}$-tests by increasing suPAR quartiles or blood eosinophil count groups, compared to patients without an event during the follow-up period. " $\mathrm{p}<0.05$ in comparison to "No event"

Abbreviations: COPD, chronic obstructive pulmonary disease; IQR, interquartile range; suPAR, soluble urokinase plasminogen activator receptor. 


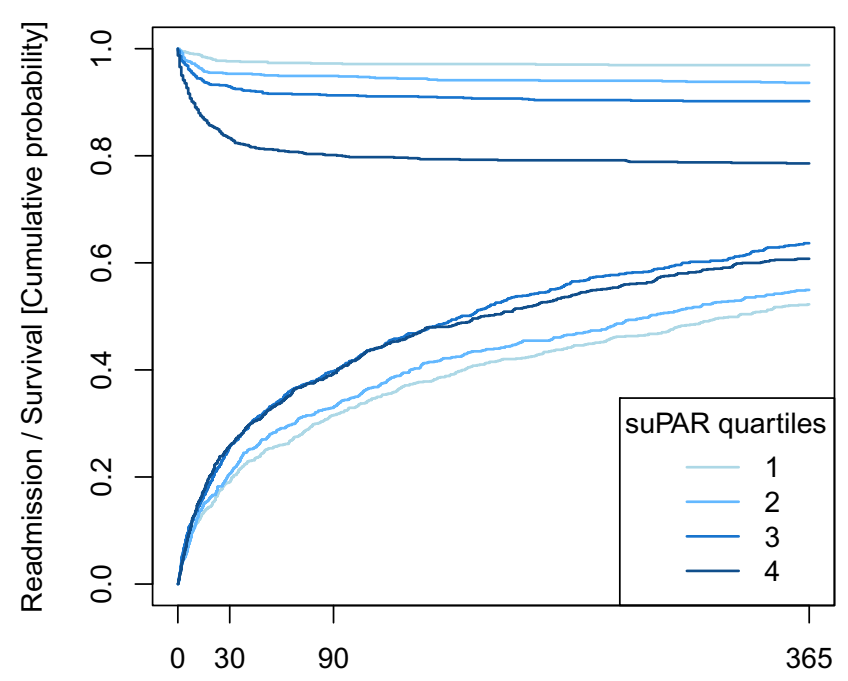

Time [Days]

Figure I Cumulative incidence plot of mortality (top) and readmission (bottom) within 365 days, stratified by quartiles of suPAR, for 4022 patients acutely admitted with chronic obstructive pulmonary disease.

achieved using the YI calculated optimal cut-off of 4.5 $\mathrm{ng} / \mathrm{mL}$. Corresponding results using the fourth quartile cutoff $(5.6 \mathrm{ng} / \mathrm{mL})$ were sensitivity $45.7 \%$ and specificity $81.7 \%$ (PPV 46.8\%, NPV 80.9\%).

\section{Blood Eosinophil Count in COPD}

For patients with COPD, median blood eosinophil count was significantly lower for patients who were readmitted compared to patients without events
(Table 3), and a trend towards a lower risk of allcause readmission was seen in patients with high blood eosinophil counts $(>300$ cells $/ \mu \mathrm{L})$ in the adjusted Cox regression analysis (HR 0.90 (95\% CI 0.80-1.02); $\mathrm{p}=0.09)$ (Table 5).

COPD patients who died during follow-up had significantly lower median blood eosinophil count at the time of index admission compared to event-free patients (Table 3). Of all deaths within 365 days, $71.0 \%(\mathrm{n}=746)$ were observed in patients with blood eosinophil counts $<150$ cells $/ \mu \mathrm{L}$ (Table 3). In patients with high blood eosinophil counts ( $>300$ cells $/ \mu \mathrm{L})$, the HR reached 0.49 (95\% CI $0.39-0.62)$ for 365-day mortality in the adjusted model (Table 5).

In ROC curve analyses, the AUC for blood eosinophil count was 0.56 (95\% CI 0.54-0.58) for predicting all-cause readmission (Supplementary Figure 1) and 0.63 (95\% CI 0.61-0.65) for predicting mortality (Supplementary Figure 2).

For predicting 365-day all-cause readmission, a cut-off for blood eosinophil count determined by YI of 5 cells $/ \mu$ L yielded a sensitivity of $88.5 \%$ and a specificity of $16.7 \%$ (PPV 59.8\%, NPV $51.0 \%$ ). Using the cut-off of 150 cells $/ \mu \mathrm{L}$ yielded a sensitivity of $39.0 \%$ and specificity of $62.0 \%$ (PPV 59.0\%, NPV 42.1\%) for predicting 365-day readmission.

For predicting 365-day mortality, a cut-off for blood eosinophil count determined by YI of 85 cells $/ \mu \mathrm{L}$ yielded a sensitivity of $62.5 \%$ and a specificity of $58.5 \%$ (PPV $34.6 \%$, NPV $81.6 \%$ ). Using the cut-off of 150 cells $/ \mu \mathrm{L}$

Table 4 HRs for Readmission and Mortality Within 365 Days Following Hospitalization in Patients with COPD ( $\mathrm{n}=4022$ ), for Continuous suPAR (Log2-Transformed) or Stratified by suPAR Quartiles

\begin{tabular}{|c|c|c|c|c|c|c|}
\hline & \multicolumn{2}{|c|}{ Respiratory Readmission } & \multicolumn{2}{|c|}{ All-Cause Readmission } & \multicolumn{2}{|c|}{ All-Cause Mortality } \\
\hline & HR (95\% Cl) & P-value & HR (95\% Cl) & P-value & HR (95\% Cl) & P-value \\
\hline \multicolumn{7}{|l|}{ Unadjusted } \\
\hline Continuous suPAR & $1.18(1.10-1.28)$ & $<0.0001$ & $1.36(1.29-1.44)$ & $<0.0001$ & $2.20(2.04-2.37)$ & $<0.0001$ \\
\hline First suPAR quartile ${ }^{b}$ & I & & 1 & & I & \\
\hline Second suPAR quartile & $0.93(0.80-1.10)$ & 0.41 & $1.13(1.00-1.27)$ & 0.054 & $1.64(1.29-2.08)$ & $<0.0001$ \\
\hline Third suPAR quartile & $1.30(1.1 I-1.5 I)$ & 0.0008 & $1.52(|.35-| .7 \mid)$ & $<0.0001$ & $2.83(2.27-3.52)$ & $<0.0001$ \\
\hline Fourth suPAR quartile & $1.28(1.10-1.50)$ & 0.0019 & $1.74(1.55-1.96)$ & $<0.0001$ & $5.49(4.46-6.76)$ & $<0.0001$ \\
\hline \multicolumn{7}{|l|}{ Multivariable $^{a}$} \\
\hline Continuous suPAR & $1.04(0.95-1.14)$ & 0.42 & $1.31(1.22-1.39)$ & $<0.0001$ & $1.76(1.62-1.92)$ & $<0.0001$ \\
\hline First suPAR quartile ${ }^{b}$ & I & & 1 & & I & \\
\hline Second suPAR quartile & $0.86(0.72-1.02)$ & 0.09 & $1.10(0.96-1.25)$ & 0.17 & $1.49(1.13-1.97)$ & 0.0050 \\
\hline Third suPAR quartile & I.II (0.93-I.32) & 0.24 & $1.44(1.27-1.64)$ & $<0.000$ I & $2.12(1.63-2.75)$ & $<0.0001$ \\
\hline Fourth suPAR quartile & $1.00(0.83-1.20)$ & 0.97 & $1.61(1.40-1.85)$ & $<0.0001$ & $3.40(2.64-4.39)$ & $<0.0001$ \\
\hline
\end{tabular}

Notes: ${ }^{a}$ Adjusted for age, sex, Charlson score, blood eosinophil count, and C-reactive protein. ${ }^{b}$ Cut-offs for the suPAR quartiles: QI: <2.9 ng/mL ( $\mathrm{n}=980,24.4 \%$ ), Q2: 2.9-3.8 ng/mL ( $\mathrm{n}=1003,24.9 \%)$ Q3: 3.9-5.5 ng/mL ( $\mathrm{n}=1014,25.2 \%), \mathrm{Q} 4: \geq 5.6 \mathrm{ng} / \mathrm{mL}(\mathrm{n}=1025,25.5 \%)$.

Abbreviations: $\mathrm{Cl}$, confidence interval; COPD, chronic obstructive pulmonary disease; HR, hazard ratio; suPAR, soluble urokinase plasminogen activator receptor. 
Table 5 HRs for Readmission and Mortality Within 365 Days Following Hospitalization in Patients with COPD (n=3849), for Continuous Blood Eosinophil Count (Log2-Transformed) or Stratified by Low, Intermediate, and High Blood Eosinophil Count

\begin{tabular}{|c|c|c|c|c|c|c|}
\hline & \multicolumn{2}{|c|}{ Respiratory Readmission } & \multicolumn{2}{|c|}{ All-Cause Readmission } & \multicolumn{2}{|c|}{ All-Cause Mortality } \\
\hline & HR (95\% Cl) & P-value & HR (95\% Cl) & P-value & HR (95\% Cl) & P-value \\
\hline \multicolumn{7}{|l|}{ Unadjusted } \\
\hline Continuous & $0.99(0.96-1.03)$ & 0.62 & $0.97(0.94-0.99)$ & $0.007 I$ & $0.83(0.79-0.86)$ & $<0.0001$ \\
\hline Low $^{\mathrm{b}}$ & 1 & & & & & \\
\hline Intermediate & $0.85(0.74-0.98)$ & 0.026 & $0.92(0.83-1.02)$ & 0.12 & $0.55(0.46-0.65)$ & $<0.0001$ \\
\hline High & $1.04(0.89-1.21)$ & 0.64 & $0.89(0.79-1.00)$ & 0.044 & $0.40(0.32-0.50)$ & $<0.0001$ \\
\hline \multicolumn{7}{|l|}{ Multivariable $^{\mathrm{a}}$} \\
\hline Continuous & $1.01(0.97-1.05)$ & 0.56 & $0.97(0.95-1.00)$ & 0.051 & $0.85(0.82-0.89)$ & $<0.0001$ \\
\hline Low $^{b}$ & 1 & & & & I & \\
\hline Intermediate & $0.88(0.76-1.02)$ & 0.10 & $0.92(0.83-1.02)$ & 0.12 & $0.60(0.50-0.7 \mathrm{I})$ & $<0.0001$ \\
\hline High & $1.09(0.93-1.27)$ & 0.28 & $0.90(0.80-1.02)$ & 0.09 & $0.49(0.39-0.62)$ & $<0.000$ I \\
\hline
\end{tabular}

Notes: ${ }^{a}$ Adjusted for age, sex, Charlson score, suPAR, and C-reactive protein. ${ }^{b}$ Cut-offs defined as Low $(<\mid 50$ cells/ $\mu \mathrm{L}, \mathrm{n}=2366)$, Intermediate $(I 50-300$ cells/ $\mu \mathrm{L}, \mathrm{n}=886)$, and High (>300 cells $/ \mu \mathrm{L}, \mathrm{n}=597)$.

Abbreviations: $\mathrm{Cl}$, confidence interval; COPD, chronic obstructive pulmonary disease; HR, hazard ratio; suPAR, soluble urokinase plasminogen activator receptor.

yielded a sensitivity of $75.8 \%$ and specificity of $40.5 \%$ (PPV $30.9 \%$, NPV $82.7 \%$ ) for predicting 365 -day mortality.

When 365-day event rates were stratified by both suPAR quartiles and blood eosinophil groups (low/intermediate/ high), all-cause readmission events were evenly distributed amongst both suPAR quartiles and blood eosinophil counts (Figure 2A). In contrast, mortality events were increasing in frequency with both increasing suPAR quartiles and decreasing blood eosinophil counts, with the group of patients belonging to the fourth suPAR quartile in combination with low blood eosinophil counts showing the highest relative mortality rate (53.0\% group mortality) (Figure $2 \mathrm{~B}$ ).

\section{Discussion}

In this study, suPAR was associated with hospital readmission and all-cause mortality in acutely admitted COPD patients. Median suPAR concentrations were consistently higher at the time of admission in patients who were either readmitted or died, and the risk of readmission and mortality was particularly high for those with the highest
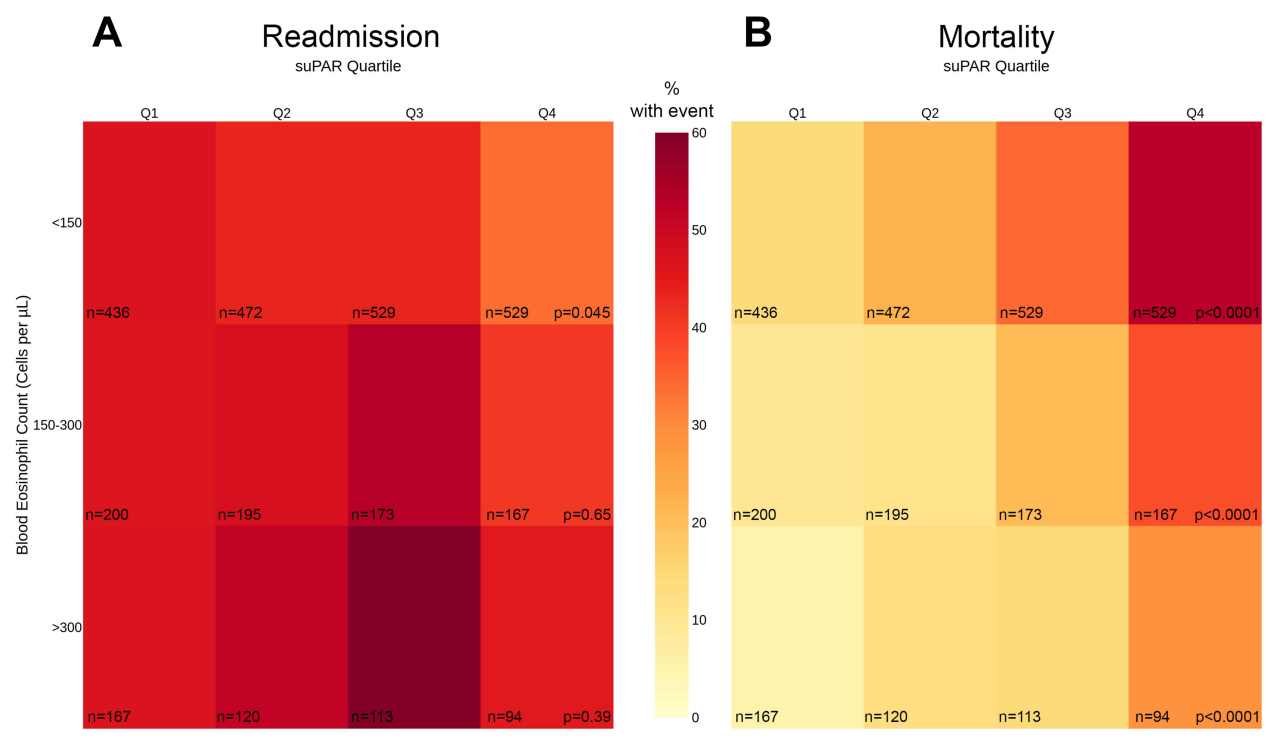

Figure 2 Heatmap of 365-days all-cause readmission (A) and mortality (B) events in 3849 patients with chronic obstructive pulmonary disease acutely admitted to a hospital, stratified by suPAR and blood eosinophil count on admission. Colors in the figure represent the percentage of patients with an event and the numbers represent the total number of patients in strata. P-values represent $\mathrm{Chi}^{2}$-tests by suPAR quartile after stratification for blood eosinophil count, versus event-free patients.

Abbreviation: suPAR, soluble urokinase plasminogen activator receptor. 
suPAR level. Furthermore, high blood eosinophil counts were associated with lower risk of all-cause mortality.

suPAR has previously been shown to be elevated in a wide range of patients with chronic diseases such as diabetes and cardiovascular disease. ${ }^{7}$ Beyond stable, chronic diseases, we have previously shown elevated suPAR to be a reliable marker for readmission and mortality in unselected, acutely admitted medical patients in an ED setting. ${ }^{7,20}$ In our previous study on a sub-set of the present study population, we showed that SuPAR was strongly associated with 30- and 90-day mortality in COPD patients. ${ }^{14}$ These findings are replicated in the current, extended cohort and are also supported by our findings of an association between suPAR and 365-day mortality. When compared to healthy controls, several studies have found elevated suPAR concentrations in (AE)COPD patients. ${ }^{13,25,26}$ In contrast, a smaller study failed to find elevated suPAR concentrations in patients with stable COPD, perhaps due to the relatively mild disease severity in patients enrolled, or due to differences in the assays used to measure suPAR.$^{27} \mathrm{~A}$ recent study has shown that suPAR concentrations in COPD patients correlate with forced expiratory volume in 1 second $\left(\mathrm{FEV}_{1}\right)$, Tiffeneau Index as well as Medical Research Council Dyspnea Score. ${ }^{28}$ Of note, suPAR was further elevated in patients with more than two exacerbations per year. ${ }^{28}$

Several intrinsic risk factors for COPD readmission are known, including low $\mathrm{FEV}_{1}$, hypoxia and comorbidities. ${ }^{29}$ Indeed, comorbidity is likely an important factor in readmission risk as approximately $40 \%$ of the initial readmissions in the present study were due to respiratory disease, and more than $30 \%$ of the cohort had a readmission caused be respiratory disease during the follow-up. This is a marked increase from previous research estimating respiratory readmissions to account for $27 \%$ of readmissions after AECOPD, ${ }^{30}$ perhaps due to the present cohort including all-cause index admissions. These findings combined with the high comorbidity burden in COPD patients highlight the need for a relatively nonspecific disease marker, when searching for a prognostic biomarker of readmission. ${ }^{31}$ However, suPAR was not independently associated with respiratory readmissions, and based on ROC curve analyses, the suPAR AUC for all-cause readmissions was poor. In contrast, suPAR demonstrated an AUC of 0.71 (95\% CI 0.69-0.72) for mortality in our cohort and a negative predictive value of $84.2 \%$ for a suPAR concentration above $4.45 \mathrm{ng} / \mathrm{mL}$, suggesting that measurement of suPAR on admission is an acceptable marker for mortality risk assessment in clinical usage. A recent study showed that suPAR outperformed standard emergency triage in predicting mortality in ED patients, and the combination of triage and suPAR $>5.7 \mathrm{ng} / \mathrm{L}$ (equivalent to the fourth suPAR quartile in the present study) yielded an AUC of 0.87 $(0.82-0.93) .^{32}$ This suggests that suPAR indeed is a viable clinical marker for all-cause mortality in acutely admitted patients with COPD.

\section{Blood Eosinophil Count, Readmission and Mortality in COPD}

We observed a trend towards lower risk of all-cause readmission in patients with blood eosinophil counts above 300 cells $/ \mu \mathrm{L}$. With respiratory readmissions in the present study being dominated by exacerbations, our results stand in contrast to the Copenhagen General Population Cohort, as well as the COPDGene and ECLIPSE cohorts, where increasing blood eosinophil count was reported to associate with increased risk of recurrent exacerbations in stable COPD. ${ }^{18,23}$ However, there is conflicting evidence with analyses of the BODE, CHAIN and SPIROMICS cohorts showing no association between blood eosinophils and increased exacerbation risk. ${ }^{33,34}$ Furthermore, and perhaps more relevant to the setting of the present study, a recent study on AECOPD also showed an increased risk of (re) exacerbation in patients with elevated blood eosinophils. ${ }^{35}$

Despite the conflicting findings on readmission, our findings on lower risk of mortality in patients with blood eosinophil counts above 300 cells $/ \mu \mathrm{L}$ are seemingly well supported in the literature with regard to AECOPD. ${ }^{33,35}$ While the overall role and mechanisms of eosinophils in COPD are still debated, post hoc analyses of the WISDOM and FLAME trials, as well as a study by Pascoe and colleagues, have found that patients with elevated blood eosinophil count respond well to corticosteroids during AECOPD. ${ }^{22,36,37}$ This might in part explain the relative increase in mortality in patients with lower blood eosinophil counts who could be considered to have a more neutrophilic inflammatory profile, representing a COPD phenotype with poorer bronchodilator and steroid therapy response, and thus a relatively high short-term mortality due to low treatment efficacy. Indeed, two smaller studies have previously associated low eosinophil counts to increased mortality in AECOPD. ${ }^{38,39}$ Eosinopenia (defined as $<40$ cells $/ \mu \mathrm{L}$ ) was associated with readmission within 30 days and has been proposed as a part of an AECOPD mortality prediction score. ${ }^{38,40}$ A plethora of biomarkers for readmission and mortality in (AE)COPD have been suggested. ${ }^{41,42}$ Common 
themes include either a panel of biomarkers or demographical data to calculate risk, but there is little coherence between studies regarding which parameters to include.

In terms of clinical performance, a cut-off of 150 cells $/ \mu \mathrm{L}$ reached a similar negative predictive value (82.7\%) for 365-day mortality prediction as suPAR. Interestingly, our study found that high suPAR concentrations $(>3.5 \mathrm{ng} / \mathrm{mL})$ were associated to higher mortality, with a majority (53.0\%) of mortality events occurring in patients with low blood eosinophil counts and high suPAR concentrations. This suggests that concurrent measurement of blood eosinophils and suPAR could hold clinical value in improving risk assessment in COPD patients in comparison to suPAR or blood eosinophils alone.

\section{Limitations}

A limitation of the present study is the lack of information on patient smoking status, as smoking has been shown to affect suPAR concentrations and isoform expression. ${ }^{43,44}$ suPAR concentrations decrease with smoking cessation, but those with the highest SUPAR concentrations while smoking also have the highest suPAR concentrations after cessation, ${ }^{45}$ and as such, we believe this possible bias to be non-differential. Furthermore, the present trial is a single-center trial, which could mean that the results are less representative for other hospitals. Confounding due to the lack of information on other clinical risk factors for readmission and mortality, such as $\mathrm{FEV}_{1}$ and dyspnea grade cannot be dismissed. The Danish patient registries used are validated, but some misdiagnoses are inevitable. All analyses were based on a single measurement at the time of index admission and thus any changes due to treatment or simple disease progression during in-hospital stay were not assessed.

In contrast to other cohorts of COPD patients, most of the patients $(55 \%)$ were women which could suggest a selection bias in our cohort. However, this could also be due to the relatively high prevalence of smoking women in Denmark, ${ }^{46}$ giving rise to a significant number of Danish women with COPD,${ }^{47}$ along with a general tendency for men with COPD in being less inclined to contact healthcare modalities overall. ${ }^{48}$ Moreover, there is evidence suggesting that women are prone to frequent, as well as more severe, exacerbations. ${ }^{49,50}$

\section{Conclusion}

To conclude, elevated suPAR was associated with increased readmission and mortality risk in COPD patients, while high blood eosinophil count was associated with lower mortality risk in COPD patients, suggesting that both biomarkers are useful in COPD. Interestingly, elevated suPAR is associated with higher mortality even in patients with low and normal blood eosinophil counts.

\section{Abbreviations}

AECOPD, Acute Exacerbation of Chronic Obstructive Pulmonary Disease; AUC, Area Under the Curve; CI, Confidence Interval; COPD, Chronic Obstructive Pulmonary Disease; CRP, C-Reactive Protein; ED, Emergency Department; $\mathrm{FEV}_{1}$, Forced Expiratory Volume, 1 second; HR, Hazard Ratio; IQR, Interquartile Range; ROC, Receiver Operating Characteristics; suPAR, Soluble Urokinase Plasminogen Activator Receptor; YI, Youden's Index.

\section{Author Contributions}

$\mathrm{KH}$ is the guarantor of this study. All authors contributed to data analysis, drafting and revising the article, gave final approval of the version to be published, and agree to be accountable for all aspects of the work.

\section{Disclosure}

OA and JEO report patents related to suPAR (methods of selecting and treating subjects with low-grade inflammation and metabolic disorders; patent number: 9645157 with royalties paid to Copenhagen University Hospital Amager and Hvidovre). JEO and LJHR report personal fees or grants, respectively, from ViroGates A/S. JEO is a CSO (current) of ViroGates A/S. LJHR was supported by a postdoctoral fellowship from the Lundbeck Foundation (grant \#R288-2018-380). JEO reports personal fees from ViroGates A/S Denmark, outside the submitted work. KM reports personal fees from Norgine, Kyowa Kirin, Chiesi Pharma, GlaxoSmithKline, Boehringer Ingelheim, Novartis, outside the submitted work. The authors report no other conflicts of interest in this work.

\section{References}

1. GOLD. Global strategy for the diagnosis, management, and prevention of COPD update 2019 2019. Available from: http:/goldcopd.org. Accessed January 5, 2019.

2. Løkke A, Hilberg O, Tønnesen P, Ibsen R, Kjellberg J, Jennum P. Direct and indirect economic and health consequences of COPD in Denmark: a national register-based study: 1998-2010. BMJ Open. 2014;4(1):e004069. doi:10.1136/bmjopen-2013-004069

3. Donaldson GC, Seemungal TAR, Bhowmik A, Wedzicha JA. Relationship between exacerbation frequency and lung function decline in chronic obstructive pulmonary disease. Thorax. 2002;57 (10):847-852. doi:10.1136/thorax.57.10.847

4. Guerrero M, Crisafulli E, Liapikou A, et al. Readmission for acute exacerbation within 30 days of discharge is associated with a subsequent progressive increase in mortality risk in COPD patients: a long-term observational study. PLoS One. 2016;11(3):e150737. doi:10.1371/journal.pone. 0150737 
5. Müllerova H, Maselli DJ, Locantore N, et al. Hospitalized exacerbations of COPD: risk factors and outcomes in the ECLIPSE cohort. Chest. 2015;147(4):999-1007. doi:10.1378/chest.14-0655

6. Lomholt FK, Laulund AS, Bjarnason NH, Jørgensen HL, Godtfredsen NS. Meta-analysis of routine blood tests as predictors of mortality in COPD. Eur Clin Respir J. 2014;1(1):24110. doi:10.3402/ecrj.v1.24110

7. Rasmussen LJH, Ladelund S, Haupt TH, et al. Soluble urokinase plasminogen activator receptor (suPAR) in acute care: a strong marker of disease presence and severity, readmission and mortality. A retrospective cohort study. Emerg Med J. 2016;33(11):769-775. doi:10.1136/emermed-2015-205444

8. Eugen-Olsen J, Andersen O, Linneberg A, et al. Circulating soluble urokinase plasminogen activator receptor predicts cancer, cardiovascular disease, diabetes and mortality in the general population. $J$ Intern Med. 2010;268(3):296-308. doi:10.1111/j.1365-2796.2010.02252.x

9. Westin O, Rasmussen LJH, Andersen O, Buch E, Olsen JE, Friberg J. Soluble Urokinase Plasminogen Activator Receptor (suPAR) as a predictor of incident atrial fibrillation. $J$ Atr Fibrillation. 2018;10:1801. doi:10.4022/jafib. 1801

10. Zhang Y, Xiao W, Jiang Y, et al. Levels of components of the urokinase-type plasminogen activator system are related to chronic obstructive pulmonary disease parenchymal destruction and airway remodelling. J Int Med Res. 2012;40(3):976-985. doi:10.1177/ 147323001204000316

11. Gussen H, Hohlstein P, Bartneck M, et al. Neutrophils are a main source of circulating suPAR predicting outcome in critical illness. $J$ Intensive Care. 2019;7(1):26. doi:10.1186/s40560-019-0381-5

12. Pliyev BK. Activated human neutrophils rapidly release the chemotactically active D2D3 form of the urokinase-type plasminogen activator receptor (uPAR/CD87). Mol Cell Biochem. 2009;321 (1-2):111-122. doi:10.1007/s11010-008-9925-z

13. Can Ü, Güzelant A, Yerlikaya FH, Yosunkaya Ş. The role of serum soluble urokinase-type plasminogen activator receptor in stable chronic obstructive pulmonary disease. J Investig Med. 2014;62 (7):938-943. doi:10.1097/JIM.0000000000000105

14. Godtfredsen NS, Jørgensen DV, Marsaa K, et al. Soluble urokinase plasminogen activator receptor predicts mortality in exacerbated COPD. Respir Res. 2018;19(1):97. doi:10.1186/s12931-018-0803-2

15. Ponce-Gallegos MA, Ramírez-Venegas A, Falfán-Valencia R. Th17 profile in COPD exacerbations. Int $J$ Chron Obstruct Pulmon Dis. 2017;12:1857-1865. doi:10.2147/COPD.S136592

16. Kang HS, Rhee CK, Kim SK, et al. Comparison of the clinical characteristics and treatment outcomes of patients requiring hospital admission to treat eosinophilic and neutrophilic exacerbations of COPD. Int J Chron Obstruct Pulmon Dis. 2016;11:2467-2473. doi:10.2147/COPD.S116072

17. Tashkin DP, Wechsler ME. Role of eosinophils in airway inflammation of chronic obstructive pulmonary disease. Int J Chron Obstruct Pulmon Dis. 2018;13:335-349. doi:10.2147/COPD.S152291

18. Vedel-Krogh S, Nielsen SF, Lange P, Vestbo J, Nordestgaard BG. Blood eosinophils and exacerbations in chronic obstructive pulmonary disease. The copenhagen general population study. Am J Respir Crit Care Med. 2016;193(9):965-974. doi:10.1164/rccm.201509-1869OC

19. Pedersen CB. The Danish civil registration system. Scand J Public Health. 2011;39(7 suppl):22-25. doi:10.1177/1403494810387965

20. Haupt TH, Petersen J, Ellekilde G, et al. Plasma suPAR levels are associated with mortality, admission time, and Charlson Comorbidity Index in the acutely admitted medical patient: a prospective observational study. Crit Care. 2012;16(4):R130. doi:10.1186/cc11434

21. Quan $\mathrm{H}, \mathrm{Li} \mathrm{B}$, Couris $\mathrm{CM}$, et al. Updating and validating the Charlson comorbidity index and score for risk adjustment in hospital discharge abstracts using data from 6 countries. Am J Epidemiol. 2011;173(6):676-682. doi:10.1093/aje/kwq433
22. Watz H, Tetzlaff K, Wouters EFM, et al. Blood eosinophil count and exacerbations in severe chronic obstructive pulmonary disease after withdrawal of inhaled corticosteroids: a post-hoc analysis of the WISDOM trial. Lancet Respir Med. 2016;4(5):390-398. doi:10.1016/ S2213-2600(16)00100-4

23. Yun JH, Lamb A, Chase R, et al. Blood eosinophil count thresholds and exacerbations in patients with chronic obstructive pulmonary disease. J Allergy Clin Immunol. 2018;141(6):2037-2047.e10. doi:10.1016/j. jaci.2018.04.010

24. Youden WJ. Index for rating diagnostic tests. Cancer. 1950;3(1):32-35. doi:10.1002/1097-0142(1950)3:1<32::aid-cncr2820030106>3.0.co;2-3

25. Gumus A, Altintas N, Cinarka H, et al. Soluble urokinase-type plasminogen activator receptor is a novel biomarker predicting acute exacerbation in COPD. Int J Chron Obstruct Pulmon Dis. 2015;10:357-365. doi:10.2147/COPD.S77654

26. Portelli MA, Siedlinski M, Stewart CE, et al. Genome-wide protein QTL mapping identifies human plasma kallikrein as a post-translational regulator of serum uPAR levels. FASEB J. 2014;28(2):923-934. doi:10.1096/fj.13-240879

27. Wang H, Yang T, Li D, et al. Elevated circulating PAI-1 levels are related to lung function decline, systemic inflammation, and small airway obstruction in chronic obstructive pulmonary disease. Int $J$ Chron Obstruct Pulmon Dis. 2016;11:2369-2376. doi:10.2147/COPD.S107409

28. Böcskei RM, Benczúr B, Losonczy G, et al. Soluble urokinase-type plasminogen activator receptor and arterial stiffness in patients with COPD. Lung. 2019;1-9. doi:10.1007/s00408-019-00211-w.

29. Coventry PA, Gemmell I, Todd CJ. Psychosocial risk factors for hospital readmission in COPD patients on early discharge services: a cohort study. BMC Pulm Med. 2011;11(1):49. doi:10.1186/1471-2466-11-49

30. Shah T, Churpek MM, Coca Perraillon M, Konetzka RT. Understanding why patients with COPD get readmitted: a large national study to delineate the Medicare population for the readmissions penalty expansion. Chest. 2015;147(5):1219-1226. doi:10.1378/chest.14-2181

31. Ställberg B, Janson C, Larsson K, et al. Real-world retrospective cohort study ARCTIC shows burden of comorbidities in Swedish COPD versus non-COPD patients. NPJ Prim Care Respir Med. 2018;28(1):33. doi:10.1038/s41533-018-0101-y

32. Schultz M, Rasmussen LJH, Kallemose T, et al. Availability of suPAR in emergency departments may improve risk stratification: a secondary analysis of the TRIAGE III trial. Scand $J$ Trauma Resusc Emerg Med. 2019;27(1):43. doi:10.1186/s13049-019-0621-7

33. Casanova C, Celli BR, De-Torres JP, et al. Prevalence of persistent blood eosinophilia: relation to outcomes in patients with COPD. Eur Respir J. 2017;50. doi:10.1183/13993003.01162-2017.

34. Hastie AT, Martinez FJ, Curtis JL, et al. Association of sputum and blood eosinophil concentrations with clinical measures of COPD severity: an analysis of the SPIROMICS cohort. Lancet Respir Med. 2017;5(12):956-967. doi:10.1016/S2213-2600(17)30432-0

35. Li Q, Larivée P, Courteau J, et al. Greater eosinophil counts at first COPD hospitalization are associated with more readmissions and fewer deaths. Int J Chron Obstruct Pulmon Dis. 2019;14:331-341. doi: $10.2147 / C O P D . S 187375$

36. Pascoe S, Locantore N, Dransfield MT, Barnes NC, Pavord ID. Blood eosinophil counts, exacerbations, and response to the addition of inhaled fluticasone furoate to vilanterol in patients with chronic obstructive pulmonary disease: a secondary analysis of data from two parallel randomised controlled trials. Lancet Respir Med. 2015;3(6):435-442. doi:10.1016/S2213-2600(15)00106-X

37. Roche N, Chapman KR, Vogelmeier CF, et al. Blood eosinophils and response to maintenance chronic obstructive pulmonary disease treatment. Data from the FLAME trial. Am J Respir Crit Care Med. 2017;195(9):1189-1197. doi:10.1164/rccm.201701-0193OC

38. Rahimi-Rad MH, Asgari B, Hosseinzadeh N, Eishi A. Eosinopenia as a marker of outcome in acute exacerbations of chronic obstructive pulmonary disease. Maedica (Buchar). 2015;10(1):10-13. 
39. Holland M, Alkhalil M, Chandromouli S, Janjua A, Babores M. Eosinopenia as a marker of mortality and length of stay in patients admitted with exacerbations of chronic obstructive pulmonary disease. Respirology. 2010;15(1):165-167. doi:10.1111/ j.1440-1843.2009.01651.x

40. Sangwan V, Chaudhry D, Malik R. Dyspnea, eosinopenia, consolidation, acidemia and atrial fibrillation score and BAP-65 score, tools for prediction of mortality in acute exacerbations of chronic obstructive pulmonary disease: a comparative pilot study. Indian J Crit Care Med. 2017;21(10):671-677. doi:10.4103/ijccm.IJCCM_148_17

41. Hurst JR, Vestbo J, Anzueto A, et al. Susceptibility to exacerbation in chronic obstructive pulmonary disease. $N$ Engl J Med. 2010;363 (12):1128-1138. doi:10.1056/NEJMoa0909883

42. Chen Y-WR, Leung JM, Sin DD. A systematic review of diagnostic biomarkers of COPD exacerbation. PLoS One. 2016;11(7):e0158843. doi:10.1371/journal.pone.0158843

43. Haupt TH, Kallemose T, Ladelund S, et al. Risk factors associated with serum levels of the inflammatory biomarker soluble urokinase plasminogen activator receptor in a general population. Biomark Insights. 2014;9:91-100. doi:10.4137/BMI.S19876

44. Portelli MA, Stewart CE, Hall IP, Brightling CE, Sayers I. Cigarette smoke and the induction of urokinase plasminogen activator receptor in vivo: selective contribution of isoforms to bronchial epithelial phenotype. Am J Respir Cell Mol Biol. 2015;53(2):174-183. doi:10. 1165/rcmb.2014-0296OC
45. Eugen-Olsen J, Ladelund S, Sørensen LT. Plasma suPAR is lowered by smoking cessation: a randomized controlled study. Eur J Clin Invest. 2016;46(4):305-311. doi:10.1111/eci.12593

46. Pisinger C, Jørgensen T, Toft U. A multifactorial approach to explaining the stagnation in national smoking rates. Dan Med J. 2018;65 (2):15.

47. Savran O, Godtfredsen N, Sørensen T, Jensen C, Ulrik CS. COPD patients prescribed inhaled corticosteroid in general practice: based on disease characteristics according to guidelines? Chron Respir Dis. n.d.;16:1479973119867949. doi:10.1177/1479973119867949

48. Henoch I, Strang S, Löfdahl C-G, Ekberg-Jansson A. Management of COPD, equal treatment across age, gender, and social situation? A register study. Int J Chron Obstruct Pulmon Dis. 2016;11:2681-2690. doi:10.21 47/COPD.S115238

49. Kilic H, Kokturk N, Sari G, Cakır M. Do females behave differently in COPD exacerbation? Int J Chron Obstruct Pulmon Dis. 2015;10:823-830. doi:10.2147/COPD.S78952

50. DeMeo DL, Ramagopalan S, Kavati A, et al. Women manifest more severe COPD symptoms across the life course. Int J Chron Obstruct Pulmon Dis. 2018;13:3021-3029. doi:10.2147/COPD.S160270

\section{Publish your work in this journal}

The International Journal of COPD is an international, peer-reviewed journal of therapeutics and pharmacology focusing on concise rapid reporting of clinical studies and reviews in COPD. Special focus is given to the pathophysiological processes underlying the disease, intervention programs, patient focused education, and self management protocols. This journal is indexed on PubMed Central, MedLine and CAS. The manuscript management system is completely online and includes a very quick and fair peer-review system, which is all easy to use. Visit http://www.dovepress.com/testimonials.php to read real quotes from published authors. 